\title{
Pranlukast prevents cysteinyl leukotriene-induced emesis in the least shrew (Cryptotis parva)
}

\author{
Seetha Chebolu ${ }^{\mathrm{a}}$, Yaozhi Wang ${ }^{\mathrm{a}, 1}$, Andrew P. Ray ${ }^{\mathrm{a}}$, and Nissar A. Darmani ${ }^{\mathrm{a}}$ \\ Seetha Chebolu: schebolu@westernu.edu; Yaozhi Wang: yaw007@ucsd.edu; Andrew P. Ray: aray@westernu.edu; Nissar \\ A. Darmani: \\ a Department of Basic Medical Science, College of Osteopathic Medicine of the Pacific, Western \\ University of Health Sciences, 309 East Second Street, Pomona, CA 91766, USA
}

\begin{abstract}
Many chemotherapeutic agents activate multiple signaling systems, including potentially emetogenic arachidonic acid metabolites. Of these messengers, the emetic role of the leukotriene family has been neglected. The aims of this study were to test the emetic potential of key leukotrienes $\left(\mathrm{LTA}_{4}\right.$, $\mathrm{LTB}_{4}, \mathrm{LTF}_{4}$, and the cysteinyl leukotrienes $\mathrm{LTC}_{4}, \mathrm{LTD}_{4}$ and $\mathrm{LTE}_{4}$ ), and to investigate whether the leukotriene CysLT $T_{1}$ receptor antagonist pranlukast or mixed leukotriene $\mathrm{CysLT}_{1 / 2}$ receptor antagonist Bay u 9773 can prevent the $\mathrm{LTC}_{4}$ induced emesis. Least shrews were injected with varying doses of one of the six tested leukotrienes and vomiting parameters measured for 30 minutes. $\mathrm{LTC}_{4}$ and $\mathrm{LTD}_{4}$ were most efficacious, and significantly increased both the frequency and percentage of animals vomiting at doses from 0.1 and $0.05 \mathrm{mg} / \mathrm{kg}$, respectively. The other tested leukotrienes were either weakly emetic or ineffective at doses up to $4 \mathrm{mg} / \mathrm{kg}$. The relative emetogenic activities of the cysteinyl leukotrienes $\left(\mathrm{LTC}_{4}=\mathrm{LTD}_{4}>\mathrm{LTE}_{4}\right)$ suggest leukotriene CysLT 2 receptors have a key role in emesis. However, pranlukast dose-dependently, and at $10 \mathrm{mg} / \mathrm{kg}$ completely, blocked $\mathrm{LTC}_{4}{ }^{-}$ induced vomiting, implicating a leukotriene CysLT 1 receptor-mediated emetic effect. Bay u9773 dose-dependently reduced the percentage of animals vomiting, but did not significantly reduce vomiting frequency. Fos immunoreactivity, measured subsequent to $\mathrm{LTC}_{4}$-induced vomiting to define its putative anatomical substrates, was significantly increased in the enteric nervous system and medullary dorsal vagal complex following $\mathrm{LTC}_{4}(\mathrm{P}<0.05)$ versus vehicle injections. This study is the first to show that some leukotrienes induce emesis, possibly involving both central and peripheral leukotriene $\mathrm{CysLT}_{1}$ and/or leukotriene $\mathrm{CysLT}_{2}$ receptors.
\end{abstract}

\section{Keywords}

Leukotriene $\mathrm{A}_{4}$; Leukotriene $\mathrm{B}_{4}$; Fos; Dorsal vagal complex; Enteric nervous system

\footnotetext{
Corresponding Author: Nissar A. Darmani, Address: Department of Basic Medical Sciences, College of Osteopathic Medicine of the Pacific, Western University of Health Sciences, 309 East Second Street, Pomona, CA 91766, USA., Tel.: 1909 469 5654; Fax: 1909 469 5577. ndarmani@westernu.edu (Nissar A. Darmani).

${ }^{1}$ Present Address: Department of Neuroscience, University of California at San Diego, 9500 Gilman Drive \# 0662, La Jolla, CA 92093, USA

Publisher's Disclaimer: This is a PDF file of an unedited manuscript that has been accepted for publication. As a service to our customers we are providing this early version of the manuscript. The manuscript will undergo copyediting, typesetting, and review of the resulting proof before it is published in its final citable form. Please note that during the production process errors may be discovered which could affect the content, and all legal disclaimers that apply to the journal pertain.
} 


\section{Introduction}

One of the most distressing side effects of antitumor treatment is chemotherapy-induced vomiting (Slatkin, 2007). Although its full mechanism has continued to elude discovery, chemotherapy-induced vomiting appears to be a multifactorial process with dopamine, serotonin, substance $\mathrm{P}$, and eicosanoids all contributing to its genesis (Andrews and Rudd, 2004; Minami et al., 2003; Darmani et al., 2009). One key eicosanoid, arachidonic acid, is released from cell membrane phospholipids by phospholipase A2. Depending on the cell and tissue type, arachidonic acid is then metabolized into different compounds by two key enzymes: 1) cyclooxygenases, which lead to formation of prostaglandins; and 2) lipoxygenases, which catalyze its conversion to hydroperoxyeicosatetraenoic acid (5-HPETE) and then to the rapidly metabolized intermediate leukotriene $\mathrm{A}_{4}\left(\mathrm{LTA}_{4}\right)$. LTA 4 is then converted to leukotriene $\mathrm{B}_{4}$ via $\mathrm{LTA}_{4}$ hydrolase or conjugated with glutathione to form the cysteinyl (or peptidyl) leukotriene, leukotriene $\mathrm{C}_{4}\left(\mathrm{LTC}_{4}\right)$. Enzymatic cleavage of specific portions of the glutathione moiety produces the other cysteinyl leukotrienes, leukotrienes $\mathrm{D}_{4}\left(\mathrm{LTD}_{4}\right)$, and $\mathrm{E}_{4}\left(\mathrm{LTE}_{4}\right)$ (Barnes, 1997; Capra et al., 2006), and also leukotriene $\mathrm{F}_{4}\left(\mathrm{LTF}_{4}\right)$, which is related to $\mathrm{LTC}_{4}$ but like $\mathrm{LTB}_{4}$ does not bind the cysteinyl leukotriene receptors. Two G-protein coupled receptors (GPCR) specific for cysteinyl leukotrienes (leukotriene CysLT 1 and leukotriene $\mathrm{CysLT}_{2}$ ) have been cloned and characterized (Kanaoka and Boyce, 2004; Figueroa et al., 2001; Heise et al., 2000). Leukotriene CysLT ${ }_{1}$ is expressed mostly in respiratory and gastrointestinal tissues and leukotriene $\mathrm{CysLT}_{2}$ in cardiovascular and brain tissues (Capra et al., 2006).

Despite the knowledge that arachidonic acid and its related metabolites (prostaglandins $\mathrm{E}_{2}$ and $\mathrm{F}_{2 \alpha}$ and their analogs) are potent emetogens (Darmani, 2002; Kan et al., 2003; Kan et al., 2006), little attention has been paid to the emetic potential of its other metabolites such as the leukotrienes. The only study that has indirectly attempted to determine the emetogenicity of the leukotrienes is the unsuccessful use of the leukotriene biosynthesis inhibitor MK-886 to block chemotherapy-induced vomiting in ferrets (Sam et al., 2007). Rather, extensive research on cysteinyl leukotrienes has examined their key role in asthma. Therefore, the aims of this study were 1) to test key leukotrienes as putative emetogens; and 2) to investigate if the currently available leukotriene CysLT $\mathrm{T}_{1}$ receptor antagonists could prevent leukotriene-induced vomiting. For this, we used the previously characterized (Barnes, 1997; Evans, 2003) human leukotriene $\mathrm{CysLT}_{1}$ receptor selective antagonist pranlukast, and the mouse leukotriene CysLT $_{1 / 2}$ dual antagonist Bay u9773 (4-[[(1R,2E,4E,6Z,9Z)-1-[(1S)-4-carboxy-1hydroxybutyl]- 2,4,6,9-pentadecatetraen-1-yl]thio]benzoic acid). Additionally, immunohistochemistry for Fos protein was used to indicate neuronal activation related to leukotriene-induced vomiting and provide information on its anatomical substrates. In this study we used the least shrew (Cryptotis parva), an emesis-competent mammal whose responses to common emetogens are well defined and correlate well with human responses (Darmani, 1998; Darmani et al., 2008).

\section{Materials and Methods}

\subsection{Animals}

Adult least shrews (C. parva) were bred in the animal facility at Western university. Previous studies had demonstrated no gender differences, so both males and females were used. They were housed in groups on a 14:10 light:dark cycle, fed with food and water ad libitum. All the shrews used were $45-60$ days old and weighed between $4-5 \mathrm{~g}$. All experiments were conducted between 9:00 and 16:00 $\mathrm{h}$ and in accordance with Western University IACUC standards. 


\subsection{Drugs}

Pranlukast, Bay u9773, $\mathrm{LTA}_{4}, \mathrm{LTB}_{4}, \mathrm{LTC}_{4}, \mathrm{LTD}_{4}, \mathrm{LTE}_{4}$ and $\mathrm{LTF}_{4}$ were purchased from Cayman Chemicals. All the leukotrienes were supplied in ethanol. The ethanol was evaporated under nitrogen and the drug was dissolved to twice the stated concentrations in a 1:1:18 solution of ethanol: emulphor ${ }^{\mathrm{TM}}$ : $0.9 \%$ saline. This solution was then diluted with an equal volume of saline to a final ethanol concentration of 2.5\%. Pranlukast and Bay u9773 were dissolved to twice the stated concentrations in DMSO and this was then diluted with an equal volume of distilled water to a final DMSO concentration of $50 \%$.

\subsection{Experimental protocols}

On the day of the experiment, shrews were brought from the animal facility, separated into individual cages and allowed to adapt for at least two hours. One hour before the experiment food was withheld. The experiment was initiated when the shrews were injected intraperitoneally (i.p.) with either the vehicle for control animals, or one of the different leukotrienes at varying doses $(0.025,0.0375,0.05,0.1,0.25,0.5,1,2$ or $4 \mathrm{mg} / \mathrm{kg}, \mathrm{n}=5-18$ per dose). Each individual shrew received one dose of one leukotriene only. Shrews were given 4 mealworms each prior to the injections, to aid in identifying wet vomits as described previously (Darmani et al., 1998). The shrews were observed for $30 \mathrm{~min}$ for vomiting behavior (number of animals vomiting within groups and frequency of vomits). Animals were used once and then euthanized with an overdose of pentobarbital ( $100 \mathrm{mg} / \mathrm{kg}$ i.p.) following the behavioral studies. Some were transcardially perfused with paraformaldehyde solution following anesthesia for use in subsequent immunohistochemical (Fos immunoreactivity) studies (see below).

For the agonist-antagonist studies, pranlukast $(0,2.5,5$ or $10 \mathrm{mg} / \mathrm{kg}, \mathrm{n}=7-11$ per dose $)$ or Bay u9773 ( 1 or $5 \mathrm{mg} / \mathrm{kg}, \mathrm{n}=6-8$ per dose) was injected at $0 \mathrm{~min}$. Immediately after this injection, shrews were given 4 mealworms each, and 30 min later the leukotriene agonist $(1 \mathrm{mg} / \mathrm{kg}$ $\mathrm{LTC}_{4}$ ) was injected. The agonist was chosen on the basis at which it caused maximum emesis in all tested animals at the lowest dosage. Each treated shrew was observed for 30 min post agonist injection and the number of animals vomiting within groups and frequency of vomits were recorded. Animals were euthanized with an overdose of pentobarbital $(100 \mathrm{mg} / \mathrm{kg}$ i.p. $)$ following the behavioral studies.

Immunohistochemical procedures were used to support the behavioral data and identify potential anatomical sites of action of leukotriene-mediated vomiting, and were performed as described elsewhere (Ray et al., 2009b). The number of Fos-immunoreactive (Fos-positive) nuclei resulting from $\mathrm{LTC}_{4}$-induced vomiting versus non-vomiting, vehicle-injected shrews was compared in brain and gut regions previously found to be associated with emesis (i.e., the dorsal vagal complex and enteric nervous system of the small intestine). The brains, as well as intestinal sections $2 \mathrm{~cm}$ long, beginning $1 \mathrm{~cm}$ from the stomach, were taken from transcardially perfused shrews used in either control or $\mathrm{LTC}_{4}$-treated behavioral groups. All tissue was processed immunohistochemically using the same methods (Ray et al., 2009b) regardless of its source.

\subsection{Statistical analysis}

The vomiting frequency data and dose-dependence were analyzed using the Kruskal-Wallis non-parametric analysis of variance (ANOVA). Animals within a group which did not vomit were still counted (as a zero frequency) for the purpose of statistical analysis. The percentage of animals vomiting across groups at different doses was compared using the Mann-Whitney $U$ test. The mean numbers of Fos-positive nuclei across vomiting and non-vomiting conditions were counted by an observer blind to the drug condition and analyzed via Student's t-test. Nuclei were counted on a per section basis in all tissues. In the ENS, sections were also subdivided into $20 \mu \mathrm{m}$ lengths for counting because the oblique sectioning made identifying 
individual enteric ganglia difficult in some sections. In all cases, a P-value $<0.05$ was necessary for statistical significance.

\section{Results}

\subsection{Leukotrienes dose-response emesis studies}

The different leukotrienes tested were $\mathrm{LTA}_{4}, \mathrm{LTB}_{4}, \mathrm{LTC}_{4}, \mathrm{LTD}_{4}, \mathrm{LTE}_{4}$ and $\mathrm{LTF}_{4}$. As mentioned, $\mathrm{LTC}_{4}, \mathrm{LTD}_{4}$, and $\mathrm{LTE}_{4}$ are the cysteinyl leukotrienes.

3.1.1 Cysteinyl leukotrienes-Dose-response vomiting behavior data for the cysteinyl leukotrienes are presented in Fig. 1. Both $\mathrm{LTC}_{4}$ (Fig. 1A, B) and LTD 4 (Fig. 1C, D) showed dose-dependent increases in vomiting behaviors. Compared to vehicle injection, $\mathrm{LTC}_{4}$ demonstrated significantly higher frequencies of vomiting $(\mathrm{P}<0.05)$ at doses greater than 0.05 $\mathrm{mg} / \mathrm{kg}$, and significant percentage of animals vomited $(\mathrm{P}<0.05)$ at doses greater than $0.1 \mathrm{mg} /$ $\mathrm{kg}$. $\mathrm{LTD}_{4}$ had a significantly greater frequency of vomiting $(\mathrm{P}<0.05)$ and percentage of animals vomiting $(\mathrm{P}<0.05)$ at all tested doses from $0.05-2 \mathrm{mg} / \mathrm{kg}$. Only $\mathrm{LTC}_{4}$ produced $100 \%$ vomiting, at the $1 \mathrm{mg} / \mathrm{kg}$ dosage $(U 84,0 ; \mathrm{P}<0.0005)$, while $\mathrm{LTD}_{4}$ produced $91 \%$ vomiting at the same dosage $(U=126,6 ; \mathrm{P}<0.0005)$. $\mathrm{LTE}_{4}$ demonstrated significant increases in the vomiting frequency $(\mathrm{P}<0.05)$ and the percentage of animals vomiting $(\mathrm{P}<0.05)$ at doses greater than 1 and $2 \mathrm{mg} / \mathrm{kg}$, respectively (Fig. 1E, F).

3.1.2. Non-cysteinyl leukotrienes-As shown in Fig. $2 \mathrm{~A} / \mathrm{B}, \mathrm{LTA}_{4}$ administration caused significant emesis only at its highest tested $(4 \mathrm{mg} / \mathrm{kg})$ dose (frequency, $\mathrm{P}<0.01$; percentage vomiting, $U=114,42 ; \mathrm{P}<0.02$ ) when compared to the vehicle treated group. $\mathrm{LTB}_{4}$ failed to induce significant vomiting at doses up to $4 \mathrm{mg} / \mathrm{kg}$ (Fig. 2C, D). On the other hand, $\mathrm{LTF}_{4}$ injection caused emesis in 36-40\% of shrews ( $\mathrm{P}<0.05, \mathrm{U}=84,36$; $\mathrm{P}<0.05, U=42,18$, respectively) at 1 and $4 \mathrm{mg} / \mathrm{kg}$ doses, statistically significant when compared against vehicle treated controls. However, $\mathrm{LTF}_{4}$ showed a significant increase in emesis frequency at $1 \mathrm{mg} /$ $\mathrm{kg}(\mathrm{P}<0.05)$ but not at the $4 \mathrm{mg} / \mathrm{kg}$ dose $(\mathrm{P}>0.05)$ (Fig. 2E, F).

As noted in Fig. 1A and B, the most potent emetic responses occurred with $\mathrm{LTC}_{4}$ at the $1 \mathrm{mg} /$ $\mathrm{kg}$ dose. Hence, $\mathrm{LTC}_{4}$ was chosen as the agonist for the subsequent agonist-antagonist studies.

\subsection{The effects of pranlukast and Bay u9773 pretreatment on $\mathrm{LTC}_{4}$-induced vomiting}

Pranlukast pretreatment (i.p.) blocked $\mathrm{LTC}_{4}$-induced emesis in a dose-dependent manner (Fig. 3). As shown in Fig. 3A/B, when compared with the vehicle injection, pranlukast pretreatment significantly reduced the frequency of vomiting at $5(\mathrm{P}=0.005)$ and $10 \mathrm{mg} / \mathrm{kg}(\mathrm{p}<0.0005)$ by $80 \%$ and $100 \%$ respectively. The percentage of animals vomiting was also significantly reduced at the $5(U=52.5,10.5 ; \mathrm{P}<0.01)$ and $10 \mathrm{mg} / \mathrm{kg}(U=56,0 ; \mathrm{P}<0.0005)$ doses (Fig. 3B). To control for possible effects on emesis generated by the antagonists themselves, each was tested alone for vomiting behavior induction. No dose of pranlukast $(1-10 \mathrm{mg} / \mathrm{kg})$ induced significant vomiting by itself (no shrews vomited at all). After Bay u9773 injection, 1 in 5 shrews $(1 \mathrm{mg} / \mathrm{kg})$ and 1 in 6 shrews $(5 \mathrm{mg} / \mathrm{kg})$ vomited one time each, but the effect was not significant $(\mathrm{P}>0.05)$.

Pretreatment (i.p.) with Bay u9773 produced a dose-dependent decrease in vomiting induced by $\mathrm{LTC}_{4}(\mathrm{P}<0.05)$. A significant decrease in the percentage of animals vomiting was noted at its $5 \mathrm{mg} / \mathrm{kg}$ dose (100\% vs. 33\%, P < 0.05 ) (Fig. 3D). However, only a trend towards reduction in the frequency of induced emesis was noted and the difference failed to achieve significance at either doses of Bay u9773 (Fig. 3C). 


\subsection{Fos immunoreactivity following $\mathrm{LTC}_{4}$ injections}

Representative photomicrographs demonstrating Fos-IR in the brain and intestine are presented in Fig. 4. The number of Fos-immunopositive nuclei following LTC $_{4}$-induced vomiting seen in the enteric nervous system and the dorsal vagal complex is shown in Fig. 5 and compared to non-vomiting, vehicle-injected controls. The dorsal vagal complex was subdivided for counting purposes into its traditionally-described component nuclei, the dorsal motor nucleus of the vagus, nucleus of the solitary tract, and area postrema (Ray et al., 2009b). Fos-IR nuclei were significantly more numerous in the $\mathrm{LTC}_{4}$-injected shrews relative to vehicle-injected, non-vomiting controls, in the dorsal motor nucleus of the vagus $(\mathrm{P}<0.05$, Fig. $5 \mathrm{~A})$ and nucleus of the solitary tract ( $\mathrm{P}<0.05$, Fig. 5B), but not in the area postrema (Fig. 5C). The enteric nervous system also demonstrated significantly more Fos-IR nuclei $(\mathrm{P}<0.05$, Fig. 5D) following $\mathrm{LTC}_{4}$ injection.

\section{Discussion}

This study is the first to show that the cysteinyl leukotrienes $\mathrm{LTC}_{4}$ and $\mathrm{LTD}_{4}$ are emetic in least shrews, and that pranlukast, an antagonist at the human cysteinyl leukotriene CysLT 1 receptor, can block the $\mathrm{LTC}_{4}$-induced vomiting. Also of note, Bay u9773, the dual antagonist of both leukotriene CysLT ${ }_{1 / 2}$ receptor subtypes, demonstrated a dose-dependent decrease in $\mathrm{LTC}_{4}$-induced emesis as well. The emetogenic activity of cysteinyl leukotrienes appears to be a specific effect, as the non-cysteinyl leukotrienes tested were at best weak, and more often ineffective, emetogens.

\subsection{Behavioral effects of leukotrienes}

As mentioned previously, the cysteinyl leukotrienes exert their effects by binding to two Gprotein coupled receptors, $\mathrm{CysLT}_{1}$ and $\mathrm{CysLT}_{2}$. The rank order binding potency in mice and humans for leukotriene CysLT 1 is $\mathrm{LTD}_{4} \gg \mathrm{LTC}_{4}>\mathrm{LTE}_{4}$, and for leukotriene CysLT $\mathrm{C}_{2}$ is $\mathrm{LTC}_{4}=\mathrm{LTD}_{4} \gg \mathrm{LTE}_{4}$ (for review see Liu et al., 2003; Evans, 2003). In this study, the rank order of emetic potency in least shrews for the cysteinyl leukotrienes was $\mathrm{LTC}_{4}=\mathrm{LTD}_{4}>$ $\mathrm{LTE}_{4}$, and thus most closely resembles the binding affinity for the leukotriene CysLT 2 receptor. However, pranlukast efficiently blocked $\mathrm{LTC}_{4}$-induced emesis, despite being considered a specific leukotriene $\mathrm{CysLT}_{1}$ antagonist in humans. Thus, either pranlukast binds to leukotriene $\mathrm{CysLT}_{2}$ receptors as well as leukotriene $\mathrm{CysLT}_{1}$ receptors, or emesis expression is not strictly correlated with CysLT binding. The former explanation seems more likely based on data from other studies. For example, mouse leukotriene $\mathrm{CysLT}_{1}$ and leukotriene $\mathrm{CysLT}_{2}$ receptors were found to be similar to human receptors in binding and functional characteristics, but pranlukast still antagonized mouse leukotriene $\mathrm{CysLT}_{2}$ receptors transfected into $\mathrm{CHO}$ cells (Evans, 2003; Ogasawara et al., 2002). Therefore, these data suggest that even though there is strong evidence of pranlukast being a specific antagonist at human leukotriene $\mathrm{CysLT}_{1}$ receptors, species differences can affect its selectivity for non-human CysLT1 receptors. Indeed, Bay u9773 has been shown to be a partial agonist at human leukotriene CysLT $T_{2}$ receptors, but an antagonist at mouse leukotriene CysLT 2 receptors (Evans, 2003). Thus, species differences in shrew versus human cysteinyl leukotriene receptors might result in antagonism of least shrew leukotriene $\mathrm{CysLT}_{2}$ receptors. Furthermore, the antiemetic activity of Bay u9773 was largely similar to that of pranlukast, and could not be used to differentiate between the activated receptor subtypes. Further work will be necessary to discern which receptor subtype is predominantly involved, and whether $\mathrm{LTC}_{4}$ and $\mathrm{LTD}_{4}$ stimulate the same or different receptors preferentially.

The similarities of the emetic potency in least shrew and the published receptor-binding profiles in other species suggest a structure-activity relationship may exist. Indeed, our data indicate a critical role for the glutathione moiety of the cysteinyl leukotrienes in $\mathrm{LTC}_{4}$-mediated 
vomiting. The intact glutathione molecule is a modified tripeptide with glutamate, cysteine, and glycine residues. $\mathrm{LTC}_{4}$ has a complete glutathione conjugate bound to the lipid moiety via the cysteine's sulfur. $\mathrm{LTD}_{4}$ is enzymatically cleaved to remove the glutamate residue, and demonstrates a slight reduction in emetic activity. $\mathrm{LTE}_{4}$ is metabolized from $\mathrm{LTD}_{4}$ via removal of the glycine residue, and is therefore left with only the cysteine residue. $\mathrm{LTE}_{4}$ was only weakly emetogenic. The glycine residue appears to be important for receptor binding affinity since $\mathrm{LTF}_{4}$, which lacks only the glycine residue, either does not bind, or at best very weakly binds the cysteinyl leukotriene receptors (Lord et al., 1985). Based on the data from this study in which $\mathrm{LTC}_{4}$ and $\mathrm{LTD}_{4}$ are significantly more emetogenic than $\mathrm{LTE}_{4}$ and $\mathrm{LTF}_{4}$, both of which demonstrate similarly weak emetogenicity, the minimum prerequisite for a significant emetic response appears to be the glycine residue, while retaining the entire tripeptide provides an optimal effect. It should be noted, though, that glutathione in itself is not emetogenic (Darmani, unpublished observations), and thus the correlation of vomiting behavior with glutathione is most likely related to its ability to enhance or otherwise stabilize leukotriene CysLT receptor binding by the leukotriene molecule.

\subsection{Role of central and peripheral systems in $\mathrm{LTC}_{4}$-induced emesis}

As mentioned, human leukotriene CysLT $\mathrm{C}_{1}$ is expressed mostly in respiratory and GI tissues and human leukotriene CysLT 2 in cardiovascular and brain tissues (Capra et al., 2006). This suggests that depending on the receptor subtype(s) stimulated, leukotriene-induced emesis in least shrews could be either due to peripheral (gut $\mathrm{CysLT}_{2}$-containing), central (brain CysLT $_{1}$-containing), or combined loci. From an anatomical standpoint, it is likely that leukotrienes (via leukotriene $\mathrm{CysLT}_{1}$ receptors) can stimulate vagal afferents terminating in the GIT (Hornby, 2001). Inflammatory mediators like leukotrienes are known to activate the intracellular $\mathrm{Ca}^{+2}$ induced $\mathrm{Ca}^{+2}$ release (CICR) pool, and bring about inhibition of a post-spike hyperpolarization $\left(\mathrm{AHP}_{\text {slow }}\right)$ current present in vagal afferent terminals, which results in an increase in firing frequency (Cordoba-Rodriguez et al., 1999). Furthermore, increased firing frequency in vagal afferents also correlates with vomiting due to other emetogens (Round and Wallis, 1986; Koga and Fukuda, 1992; Minami et al., 1995; Cordoba-Rodriguez et al., 1999), and could therefore be a mechanism through which leukotrienes induce emesis. Vagal afferent neurons reside in the nodose ganglion, and bifurcating fibers projecting from the same afferent neurons terminate in both the GIT and the nucleus of the solitary tract, thus inducing activity at both the enteric and central nervous system levels, and specifically in the dorsal vagal complex. Although this activity is one possible source of Fos-IR in the dorsal vagal complex, our Fos-IR data also demonstrated that both enteric and dorsal vagal complex nuclei are activated following leukotriene-induced vomiting. Taken together, the combined data suggest that cysteinyl leukotrienes can modulate emetic activity through both peripheral and central components. When combined with the studies described above, the data imply that facilitation of vagal activity via $\mathrm{Ca}^{+2}$ signaling would be a likely mechanism for this activation.

Induction of Fos-IR nuclei in the dorsal motor nucleus of the vagus and nucleus of the solitary tract, but not in the area postrema, suggests that blood borne mediators do not have a significant role in leukotriene-induced emesis. This would be expected if injection of $\mathrm{LTC}_{4}$ was acting directly on GIT tissue or GIT-localized afferent terminals, since leukotrienes undergo rapid breakdown and function primarily as paracrine signals (Jedlitschky et al., 1993). Alternatively, as indicated for some other emetogenic stimuli (Bhandari et al., 1992; Zaman et al., 2000; Ray et al., 2009a), cysteinyl leukotriene receptors in the area postrema could be located on dendrites extending into the area postrema from nucleus of the solitary tract neurons, and would therefore not increase Fos-IR in the area postrema. This effect is rarely observed, however, as the area postrema frequently demonstrates Fos-IR related to activation by blood-borne emetogens (Ray et al., 2009a). Based on the short half-life of leukotrienes after injection combined with the lack of Fos-IR in the area postrema, the most likely hypothesis is that leukotriene-induced 
vomiting is initiated in the GIT via leukotriene CysLT 1 receptors, and central Fos-IR is induced upon activation of the nucleus of the solitary tract via vagal afferent fibers, rather than direct activation of dorsal vagal complex leukotriene $\mathrm{CysLT}_{2}$ receptors via blood-borne leukotrienes. It should be noted, though, that Fos-IR is a correlative measure, and Fos-IR in the enteric nervous system could be due to the output (motor response) phase rather than the initiation phase of vomiting. In addition, evidence has accumulated that cysteinyl leukotrienes themselves can increase the permeability of the blood-brain barrier (Chio et al., 1992) or be transported by multidrug resistance proteins (Liu et al., 2009). Thus, a direct central mechanism cannot be completely ruled out.

In conclusion, our study is the first to show leukotrienes cause emetic behavior, which could be successfully blocked by the specific cysteinyl leukotriene receptor antagonists pranlukast and Bay u9773. Further work will be necessary to define the specific mechanism through which leukotrienes induce vomiting, as well as whether vomiting related to inflammation occurs separately but in parallel with vomiting caused by other emetogens (e.g. cisplatin), or whether it acts in concert with them to increase the severity of vomiting induced by those other emetogens.

\section{Acknowledgments}

This work was supported by NIH grant \# R01CA115331 from the National Cancer Institute to Dr. Darmani.

\section{References}

Andrews, PLR.; Rudd, JA. The role of tachykinins and the tachykinin $\mathrm{NK}_{1}$ receptor in nausea and emesis. In: Holzer, P., editor. Handbook of Experimental Pharmacology. Springer-Verlag; New York: 2004. p. 359-440.

Barnes N. Leukotriene receptor antagonists: clinical effects. J R Soc Med 1997;90:200-204. [PubMed: 9155753]

Bhandari P, Bingham S, Andrews PL. The neuropharmacology of loperamide-induced emesis in the ferret: the role of the area postrema, vagus, opiate and 5-HT3 receptors. Neuropharmacology 1992;31:735-742. [PubMed: 1326727]

Capra V, Ambrosio M, Riccioni G, Rovati GE. Cysteinyl-leukotriene receptor antagonists: present situation and future opportunities. Curr Med Chem 2006;13:3213-3226. [PubMed: 17168708]

Chio CC, Baba T, Black KL. Selective blood-tumor barrier disruption by leukotrienes. J Neurosurg 1992;77:407. [PubMed: 1506887]

Cordoba-Rodriguez R, Moore KA, Kao JP, Weinreich D. Calcium regulation of a slow post-spike hyperpolarization in vagal afferent neurons. Proc Natl Acad Sci U S A 1999;96:7650-7657. [PubMed: 10393875]

Darmani NA. Serotonin 5-HT3 receptor antagonists prevent cisplatin-induced emesis in Cryptotis parva: a new experimental model of emesis. J Neural Transm 1998;105:1143-1154. [PubMed: 9928884]

Darmani NA. The potent emetogenic effects of the endocannabinoid 2-AG (2-arachidonoylglycerol) are blocked by delta(9)-tetrahydrocannabinol and other cannabinoids. J Pharmacol Exp Therap 2002;300:34-42. [PubMed: 11752094]

Darmani NA, Wang Y, Abad J, Ray AP, Thrush GR, Ramirez J. Utilization of the least shrew as a rapid and selective screening model for the antiemetic potential and brain penetration of substance $\mathrm{P}$ and NK1 receptor antagonists. Brain Res 2008;1214:58-72. [PubMed: 18471804]

Darmani NA, Crim JL, Janoyan JJ, Abad J, Ramirez J. A re-evaluation of the neurotransmitter basis of chemotherapy-induced immediate and delayed vomiting: evidence from the least shrew. Brain Res 2009;1248:40-58. [PubMed: 19022231]

Evans JF. The cysteinyl leukotriene receptors. Prostaglandins Leukot Essent Fatty Acids 2003;69:117122. [PubMed: 12895594]

Figueroa DJ, Breyer RM, Defoe SK, Kargman S, Daugherty BL, Waldburger K, Liu Q, Clements M, Zeng Z, O’Neill GP, Jones TR, Lynch KR, Austin CP, Evans JF. Expression of the cysteinyl 
leukotriene 1 receptor in normal human lung and peripheral blood leukocytes. Am J Respir Crit Care Med 2001;163:226-233. [PubMed: 11208650]

Heise CE, O'Dowd BF, Figueroa DJ, Sawyer N, Nguyen T, Im DS, Stocco R, Bellefeuille JN, Abramovitz M, Cheng R, Williams DL Jr, Zeng Z, Liu Q, Ma L, Clements MK, Coulombe N, Liu Y, Austin CP, George SR, O'Neill GP, Metters KM, Lynch KR, Evans JF. Characterization of the human cysteinyl leukotriene 2 receptor. J Biol Chem 2000;275:30531-30536. [PubMed: 10851239]

Hornby PJ. Central neurocircuitry associated with emesis. Am J Med 2001;111(Suppl 8A):106S-112S. [PubMed: 11749934]

Jedlitschky G, Mayatepek E, Keppler D. Peroxisomal leukotriene degradation: biochemical and clinical implications. Adv Enzyme Regul 1993;33:181-194. [PubMed: 8356907]

Kan KK, Jones RL, Ngan MP, Rudd JA. Action of prostanoids on the emetic reflex of Suncus murinus (the house musk shrew). Eur J Pharmacol 2003;477:247-251. [PubMed: 14522363]

Kan KK, Rudd JA, Wai MK. Differential action of anti-emetic drugs on defecation and emesis induced by prostaglandin E2 in the ferret. Eur J Pharmacol 2006;544:153-159. [PubMed: 16844111]

Kanaoka Y, Boyce JA. Cysteinyl leukotrienes and their receptors: cellular distribution and function in immune and inflammatory responses. J Immunol 2004;173:1503-1510. [PubMed: 15265876]

Koga T, Fukuda H. Neurons in the nucleus of the solitary tract mediating inputs from emetic vagal afferents and the area postrema to the pattern generator for the emetic act in dogs. Neurosci Res 1992;14:166-179. [PubMed: 1331921]

Liu S, Hu HZ, Gao C, Gao N, Wang G, Wang X, Gao X, Xia Y, Wood JD. Actions of cysteinyl leukotrienes in the enteric nervous system of guinea-pig stomach and small intestine. Eur J Pharmacol 2003;459:27-39. [PubMed: 12505531]

Liu YH, Di YM, Zhou ZW, Mo SL, Zhou SF. Multidrug Resistance Associated Proteins and Implications in Drug Development. Clin Exp Pharmacol Physiol. 2009 E-published ahead of print.

Lord A, Charleson S, Letts LG. Leukotriene F4 and the release of arachidonic acid metabolites from perfused guinea pig lungs in vitro. Prostaglandins 1985;29:651-660. [PubMed: 3923570]

Minami M, Endo T, Hirafuji M, Hamaue N, Liu Y, Hiroshige T, Nemoto M, Saito H, Yoshioka M. Pharmacological aspects of anticancer drug-induced emesis with emphasis on serotonin release and vagal nerve activity. Pharmacol Ther 2003;99:149-165. [PubMed: 12888110]

Minami M, Tamakai H, Ogawa T, Endo T, Hamaue N, Hirafuji M, Yoshioka M, Blower PR. Chemical modulation of 5-HT3 and 5-HT4 receptors affects the release of 5-hydroxytryptamine from the ferret and rat intestine. Res Commun Mol Pathol Pharmacol 1995;89:131-142. [PubMed: 8556268]

Ogasawara H, Ishii S, Yokomizo T, Kakinuma T, Komine M, Tamaki K, Shimizu T, Izumi T. Characterization of mouse cysteinyl leukotriene receptors mCysLT1 and mCysLT2: differential pharmacological properties and tissue distribution. J Biol Chem 2002;277:18763-18768. [PubMed: 11854273]

Ray AP, Chebolu S, Darmani NA. Receptor-selective agonists induce emesis and Fos expression in the brain and enteric nervous system of the least shrew (Cryptotis parva). Pharmacol Biochem Behav 2009a;94:211-218. [PubMed: 19699757]

Ray AP, Griggs L, Darmani NA. Delta 9-tetrahydrocannabinol suppresses vomiting behavior and Fos expression in both acute and delayed phases of cisplatin-induced emesis in the least shrew. Behav Brain Res 2009b;196:30-36. [PubMed: 18721829]

Round A, Wallis DI. The depolarizing action of 5-hydroxytryptamine on rabbit vagal afferent and sympathetic neurones in vitro and its selective blockade by ICS 205-930. Br J Pharmacol 1986;88:485-494. [PubMed: 3755366]

Sam TS, Ngan MP, Riendeau D, Robichaud A, Rudd JA. Action of cyclooxygenase inhibitors and a leukotriene biosynthesis inhibitor on cisplatin-induced acute and delayed emesis in the ferret. $\mathrm{J}$ Pharmacol Sci 2007;103:189-200. [PubMed: 17310074]

Slatkin NE. Cannabinoids in the treatment of chemotherapy-induced nausea and vomiting: beyond prevention of acute emesis. J Support Oncol 2007;5:1-9. [PubMed: 17566383]

Zaman S, Woods AJ, Watson JW, Reynolds DJ, Andrews PL. The effect of the NK1 receptor antagonist CP-99,994 on emesis and c-fos protein induction by loperamide in the ferret. Neuropharmacology 2000;39:316-323. [PubMed: 10670427] 

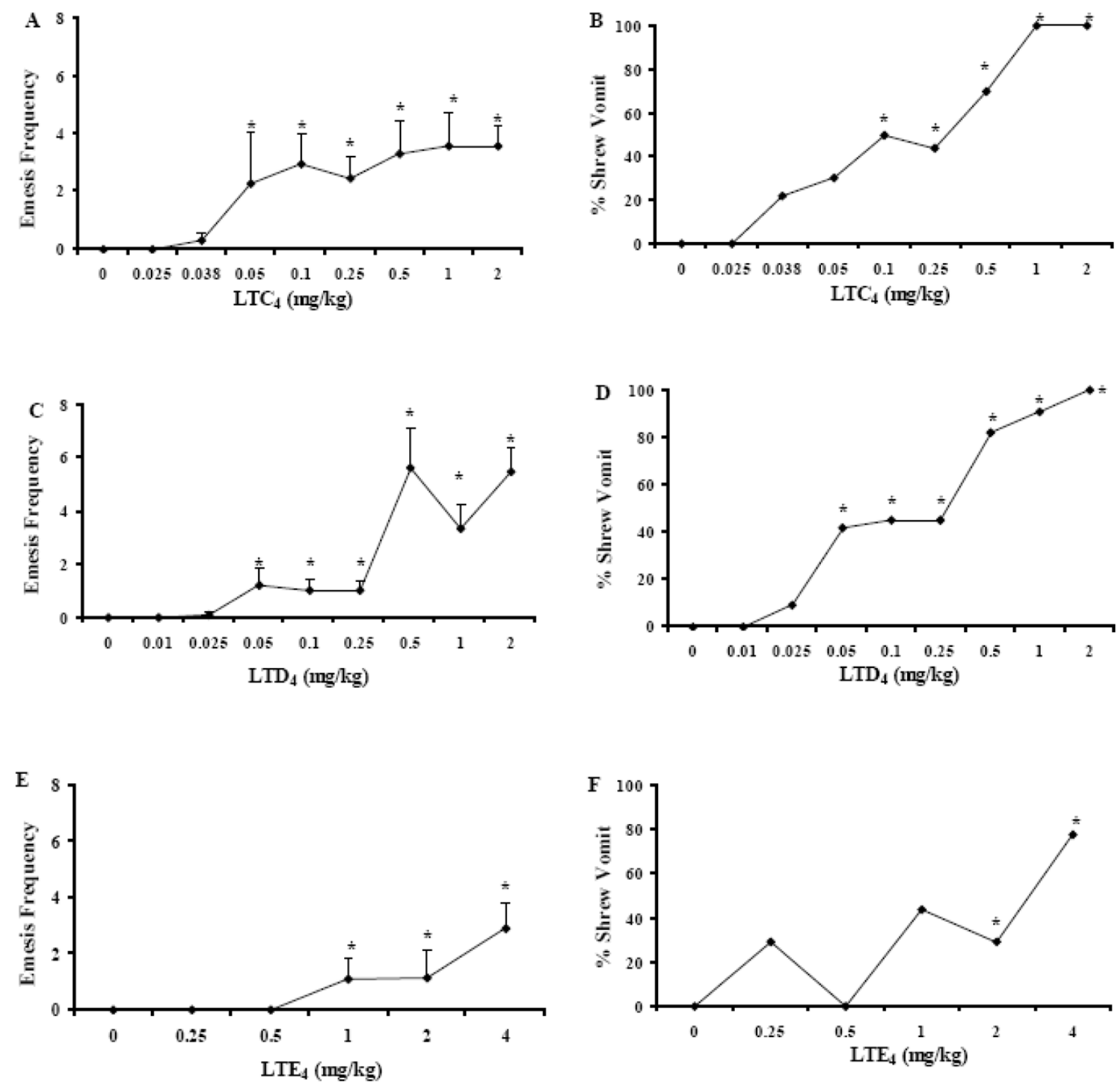

Fig. 1. The dose-dependent emetic effects of cysteinyl leukotrienes

Intraperitoneally administered cysteinyl leukotrienes ( $\mathrm{LTC}_{4}, \mathrm{LTD}_{4}$ and $\left.\mathrm{LTE}_{4}\right)$ at varying doses showed dose-dependent emetic effects in a $30 \mathrm{~min}$ post-injection observation period in the least shrew. Graphs A, C and E represent dose-response curves for the frequency of emesis (mean \pm S.E.M.) for $\mathrm{LTC}_{4}, \mathrm{LTD}_{4}$ and $\mathrm{LTE}_{4}$ respectively. Graphs B, D and F show the respective dose-response curves for the percentage of shrews in a given group that vomited in response to intraperitoneal administration of $\mathrm{LTC}_{4}, \mathrm{LTD}_{4}$ and $\mathrm{LTE}_{4}$ respectively. $*$ Represents significant $(\mathrm{P}<0.05)$ differences from the vehicle control $(0 \mathrm{mg} / \mathrm{kg})$. 

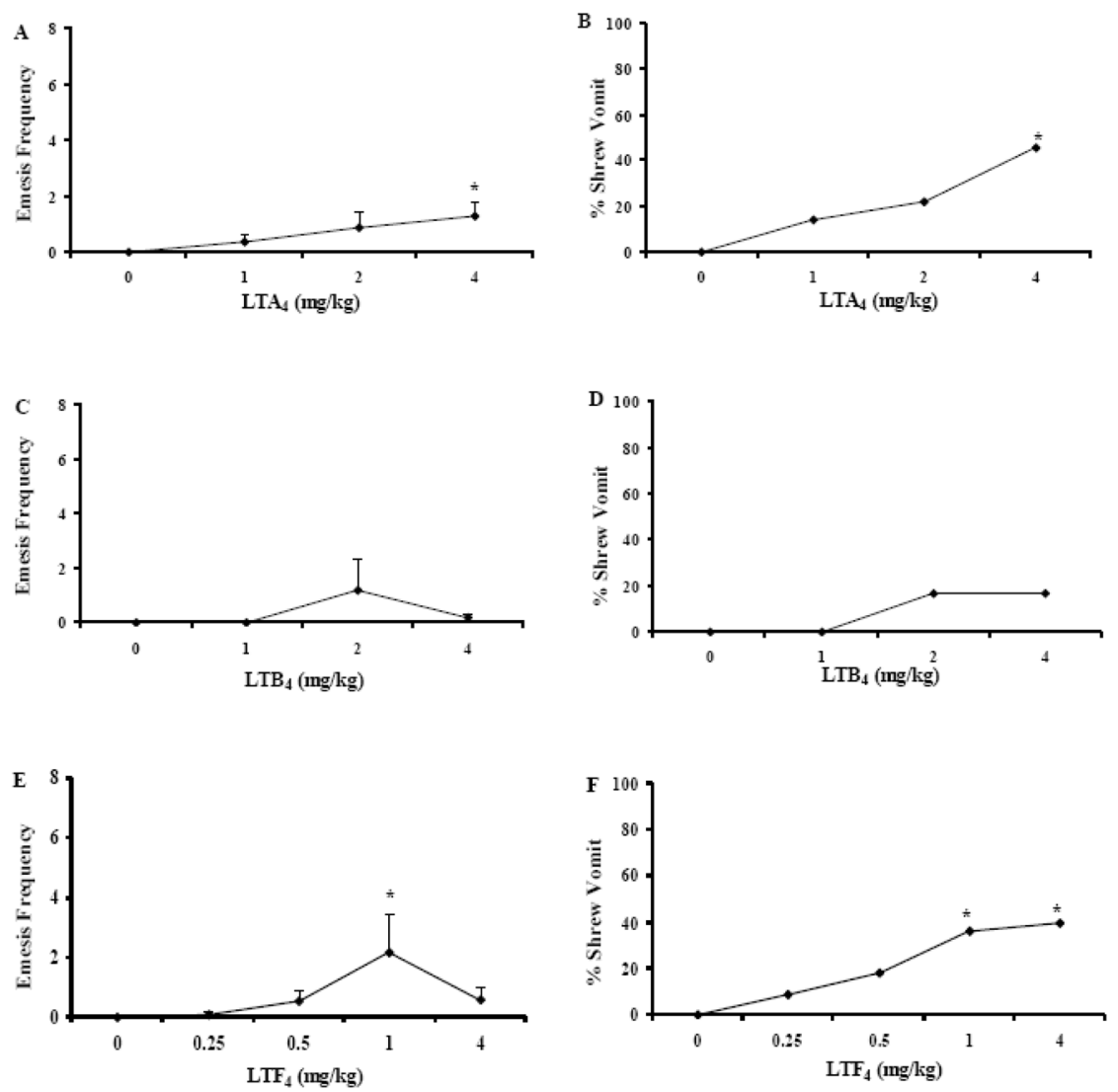

Fig. 2. The dose-dependent emetic effects of non-cysteinyl leukotrienes

Intraperitoneally administered non-cysteinyl leukotrienes ( $\mathrm{LTA}_{4}, \mathrm{LTB}_{4}$ and $\left.\mathrm{LTF}_{4}\right)$ at varying doses showed limited emetic effects in a $30 \mathrm{~min}$ post-injection observation period in the least shrew. Graphs A, C, and E represent dose-response curves for the frequency of emesis (mean \pm S.E.M.) following intraperitoneal injection of $\mathrm{LTA}_{4}, \mathrm{LTB}_{4}$ and $\mathrm{LTF}_{4}$, respectively. Graphs $\mathrm{B}, \mathrm{D}$ and $\mathrm{F}$ show the respective dose-response curves for the percentage of shrews in a given group that vomited in response to $\mathrm{LTA}_{4}, \mathrm{LTB}_{4}$ and $\mathrm{LTF}_{4}$ injection. * Represents significant $(\mathrm{P}<0.05)$ differences from the vehicle control $(0 \mathrm{mg} / \mathrm{kg})$. 

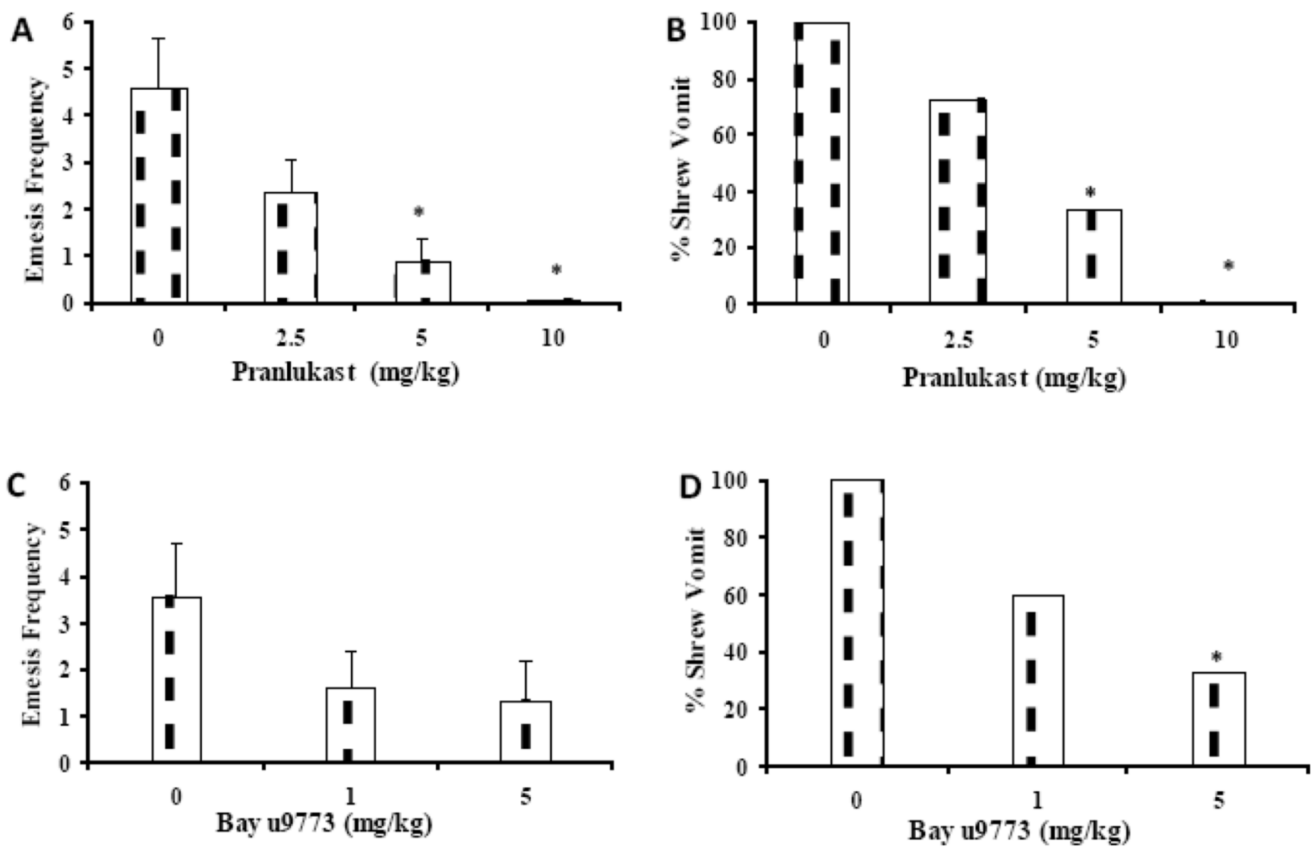

Fig. 3. Dose-dependent inhibitory effects of Pranlukast and Bay u9773 on vomiting parameters induced by $\mathrm{LTC}_{4}$ injection

Prior intraperitoneal administration of the cited doses of either pranlukast (graphs A and B) or Bay u9773 (graphs C and D), attenuated both the frequency ( \pm S.E.M.) and the percentage of shrews vomiting in response to an intraperitoneal injection of $1 \mathrm{mg} / \mathrm{kg}$ dose of $\mathrm{LTC}_{4}$ in the 30 min observation period following emetogen administration. * Represents a statistically significant $(\mathrm{P}<0.05)$ reduction in vomiting versus vehicle-pretreated controls. 


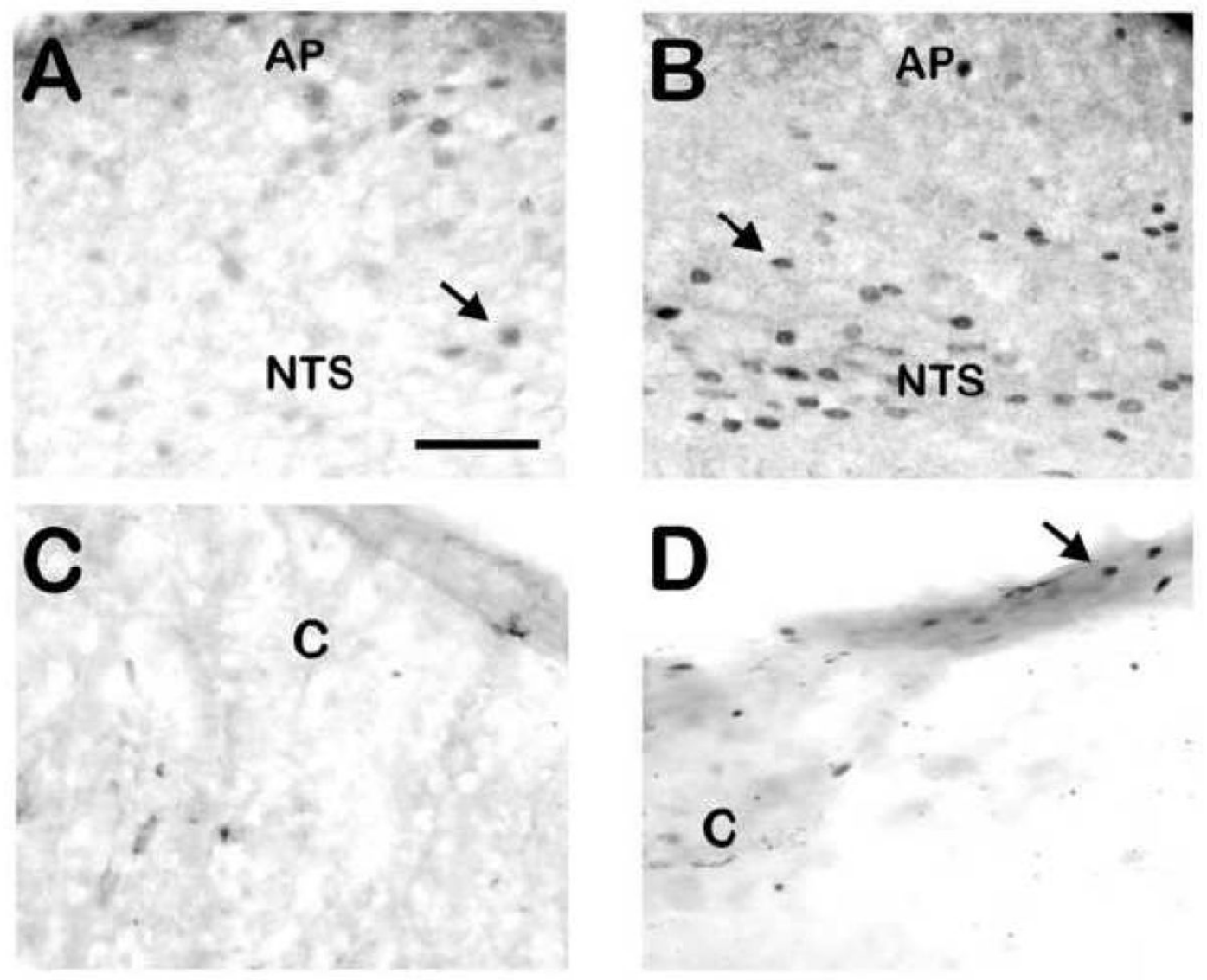

Fig. 4. Examples of Fos-immunoreactive nuclei in the dorsal vagal complex (DVC) and enteric nervous system (ENS)

Arrows point to examples of Fos-IR nuclei. Brain sections are cut sagittally, and intestinal sections are cut at an oblique angle to the longitudinal axis. A) Fos-IR nuclei in the dorsal vagal complex of vehicle-injected controls. Modest expression of Fos is normal in the brains of freely-behaving animals. B) Fos-IR in the NTS and AP of LTC 4 -injected ( $1 \mathrm{mg} / \mathrm{kg}$, i.p.) shrews. Note the increased expression in the NTS, but not the AP. The DMNX is not present at this level, but appeared similar to the NTS in terms of degree of labeling. C) Fos-IR in the intestine of vehicle-injected controls. Very little or no Fos was expressed in the ENS. D) Fos-IR was induced in the intestine of $\mathrm{LTC}_{4}$-injected shrews. The sections shown in $\mathrm{C}$ and D were morphologically similar to jejunal tissue sections. In both sections, the ENS nerve plexi were in the darker band of tissue in the top right (C) or left (D) corner adjacent to the crypts. FosIR was primarily restricted to the nerve plexi. Abbreviations: AP- area postrema, C- intestinal crypts, ENS- enteric nervous system, NTS- nucleus of the solitary tract. Scale bar for all plates $=50 \mu \mathrm{m}$. 
A

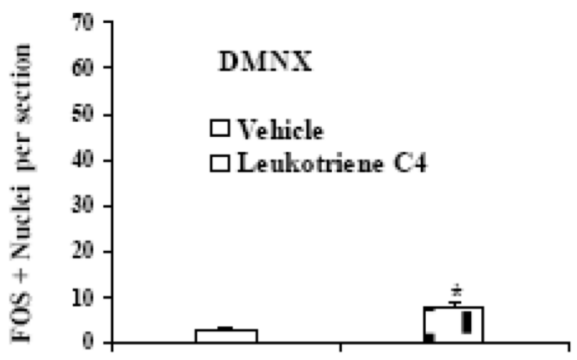

$\mathrm{C}$

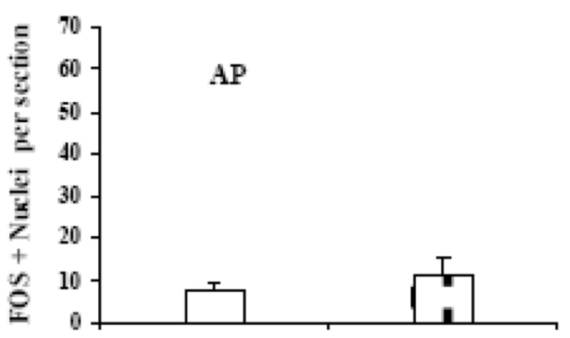

B

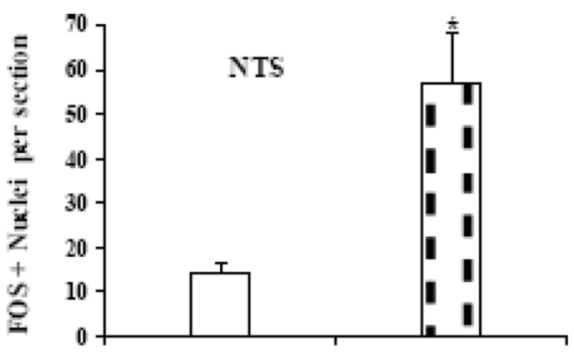

D

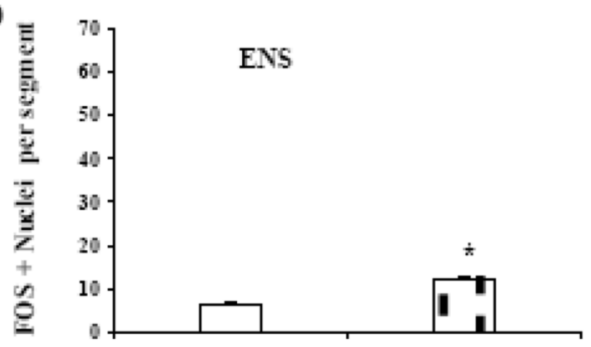

Fig. 5. Counts of Fos-immunoreactive nuclei following vehicle and leukotriene $\mathrm{C}_{4}$ injection-induced emesis

Means and standard errors of Fos-immunoreactive nuclei per section following vehicle and $\mathrm{LTC}_{4}$ injections ( $1 \mathrm{mg} / \mathrm{kg}$, i.p.) are graphed for each subdivision of the DVC (DMNX, NTS and AP) and for each $20 \mu \mathrm{m}$ length of the ENS. * Represents a significant $(\mathrm{P}<0.05)$ increase in Fos-IR nuclei versus vehicle-pretreated controls. Abbreviations: AP- area postrema, DMNX- dorsal motor nucleus of the vagus nerve, DVC- dorsal vagal complex, ENS- enteric nervous system, NTS- nucleus of the solitary tract. 